\title{
The Evaluation and Treatment of a Patient with Anorexia Nervosa
}

Gail S. Greenspan, MD

Thomas Jefferson University Hospital

Follow this and additional works at: https://jdc.jefferson.edu/jeffjpsychiatry

Part of the Psychiatry Commons

Let us know how access to this document benefits you

\section{Recommended Citation}

Greenspan, MD, Gail S. (1984) "The Evaluation and Treatment of a Patient with Anorexia Nervosa," Jefferson Journal of Psychiatry. Vol. 2 : Iss. 2 , Article 2.

DOI: https://doi.org/10.29046/JJP.002.2.001

Available at: https://jdc.jefferson.edu/jeffjpsychiatry/vol2/iss2/2

This Article is brought to you for free and open access by the Jefferson Digital Commons. The Jefferson Digital Commons is a service of Thomas Jefferson University's Center for Teaching and Learning (CTL). The Commons is a showcase for Jefferson books and journals, peer-reviewed scholarly publications, unique historical collections from the University archives, and teaching tools. The Jefferson Digital Commons allows researchers and interested readers anywhere in the world to learn about and keep up to date with Jefferson scholarship. This article has been accepted for inclusion in Jefferson Journal of Psychiatry by an authorized administrator of the Jefferson Digital Commons. For more information, please contact: JeffersonDigitalCommons@jefferson.edu. 


\title{
THE EVALUATION AND TREATMENT OF A PATIENT WITH ANOREXIA NERVOSA
}

\author{
GAIL S. GREENSPAN, M.D.
}

\section{Introduction}

Anorexia nervosa is a serious illness that has generated enormous public interest during recent times. Within the psychiatric field, numerous articles and books have been written about this syndrome. This literature reflects varied theoretical frameworks, from primarily biological approaches to family systems to psychodynamic theory. In this paper I will attempt to integrate family systems and psychodynamic theory in an understanding of a young woman with anorexia nervosa who was treated in a hospital setting.

\section{Epidemiology}

The incidence of anorexia nervosa seems to be on the rise in this country. Recent reports of its prevalence vary, and quote higher figures than those ten to fifteen years ago. In 1973 Hilde Bruch described anorexia as "rare indeed," and the medical fascination with it as "quite out of proportion to its infrequent occurrence" (1). The DSM-III lists the prevalence of anorexia as being as high as 1 in 250 females between the ages of twelve and eighteen (2). Anorexia occurs almost exclusively in females, although male cases have been reported. It is the only psychiatric disorder with a significant mortality rate ranging from six to twenty-one percent (3).

The increasing number of reports of anorexia may reflect not only an increase in the incidence of this disorder, but a greater public awareness of its existence as well. This increase in awareness reflects social values that have undoubtedly contributed to the development of this disorder. In many ways anorexia is an exaggeration of the current preoccupation with slimness. A non-anorectic female college student was quoted in a Newsweek article: "My goal is to get rid of every ounce of fat on my body-nothing will shake when I walk" (4). Contrast this with a comment from the French clinician F. Heckel in 1911: “. . . women may want to stay obese for reasons of fashionable appearance ... in order to have an impressive decollete" (5). Anorexia typically first manifests itself during adolescence. A younger age of onset is correlated with a better outcome, while onset after adolescence is usually more serious and less responsive to treatment (6).

\section{Clinical Characteristics}

Anorexia nervosa is a syndrome that is characterized by an intense fear of becoming obese, a disturbance of body image awareness, a weight loss of at least $25 \%$

Dr. Greenspan is a fourth-year resident in Psychiatry. 
from original body weight, and a refusal to maintain body weight at a normal level (2). Amenorrhea is usually present, often preceding significant weight loss. Pathognomonic of anorexia is the patient's vigorous denial of the abnormality of her cachectic body. Also characteristic is a denial of hunger with a simultaneous preoccupation with food (cooking it, thinking about it). Most patients express the fear that if they begin to eat - if they take even one bite-they will not be able to stop.

Many of the late features of anorexia may be attributable to the extreme degree of starvation (1). Obsessive ruminations about food have been observed in anorexia as well as in individuals suffering from externally induced starvation. Similarly, the infantile regression and battles for control that occur with hospitalized anorectics are later features of anorexia. After the nutritional deficiency is corrected, patients report how altered their thinking was while they were under-weight: "My thought processes became very unrealistic ... Being hungry has the same effect as a drug, and you feel outside your body ... you can undergo pain without reacting" (7).

Because these patients displace all their anxieties and fears to a constant preoccupation with staying thin, it is usually quite difficult to engage them in meaningful psychotherapy while they are seriously malnourished. It is important that the therapist not collude with the patient's own denial of her self-starvation, thus ignoring the severe degree of malnutrition present. Because weight loss in anorexia is gradual and most anorectics are usually healthy adolescents prior to the onset of this disorder, the physician's index of suspicion for underlying physical abnormalities such as cardiac arrhythmias and electrolyte imbalances may be low. Therefore, the treating physician should be familiar with the life-threatening complications that may arise in anorexia and require hospitalization (8).

The distortion of body image that occurs in anorexia has been studied by various investigators. It has been found that emaciated anorectics consistently overestimate the width of their body parts (6). They also report feeling as though their body is not their own, and describe their illness as something that is passively happening to them. Successful treatment of anorexia requires correction of the underlying distorted body image and not simply weight gain. As Bruch states, "Anorexia nervosa, by its very existence, proves that the hateful self-concept is not really related to excess weight, but to some deep inner dissatisfaction" (1).

\section{Family Dynamics}

Salvador Minuchin has written extensively on the family dynamics of anorexia nervosa. Indeed, he uses the term "anorectic family" to underline his observations of the role that the interpersonal dynamics within the family play in the eventual development of anorexia in the patient (9).

While it is difficult to delineate what constitutes a "normal" family, wellintegrated families do seem to provide two vital functions for individual members: a sense of belonging and a reference point for a sense of autonomy. There is a fluidity between these two functions that serves to support the development of a solid sense of identity in the child. 
In the family of the anorectic individual, highly enmeshed patterns of interaction predominate (9). There are well defined, often rigid boundaries separating the family unit from the external world. In contrast intrafamilial boundaries are rather blurred. Frequently the anorectic child is a "go-between" for the parents, who communicate poorly with each other. There is often a strong affiliation between one spouse and the corresponding grandparents that further maintains the distance between the spouses.

The enmeshed family is characterized by overprotectiveness and intrusive concern for other family members. The development of autonomy in the child becomes secondary to her obsessive concern with accommodating others. Thus evolves the description of the anorectic girl as "the perfect child." Parents offer testimonial that their daughter had been "the best, brightest, sweetest, most obedient, and most cooperative child ever" (7).

The "conflict-avoidance" pattern is used by these families. During interviews they state they never disagree. Often the anorectic child "feels great responsibility for not embarrassing the family in the eyes of the extrafamilial" (9). The parents deny any problems at all, except for the perplexing refusal of their daughter to eat.

During the initial phase of treatment, the immediately observable family interactions revolve around trying to force the patient to eat. It is only when these frantic, furious efforts have subsided that the underlying maladaptive patterns can be recognized.

\section{Intrapsychic Conflicts}

There has been some conflict over the classification, and therefore, the psychodynamic understanding of anorexia nervosa. Is it a psychosomatic syndrome? An obsessive-compulsive neurosis? A type of psychosis? Psychiatric studies have failed to delineate one particular underlying character structure in anorectic individuals.

I agree with Sperling, who considers anorexia a neurotic symptom complex (10). She states that anorexia can occur in a variety of patients with different character disorders, usually with pregenital fixations. Anorexia does not fit the definition of a psychosomatic disorder in which unconscious conflicts, fantasies, and affects are displaced onto various organ systems, with demonstrable changes in the structure or function of organ systems.

The underlying dynamics in anorexia are very complex. One must keep in mind the psychoanalytic concept of over-determination in order to understand the multiple unconscious meanings that emerge in the psychoanalytic treatment of anorectics (11). The anorectic displaces sexual impulses from the genital level to the oral level. Eating becomes equated with losing control completely, giving in to highly conflictual impulses.

Various unconscious fantasies have been reported in the literature. The most common fantasy is that of oral impregnation. Also common is the infantile fantasy of birth being an anal process (10). The symptoms of refusal to eat and of constipation can be seen as derivatives of these unconscious fantasies. Menstruation may be equated with castration, internal injury, and an indication of feminity, all of which must be 
avoided in order to reduce anxiety. Indeed, one of the functions of thinness is the avoidance of appearing feminine. The normal pubertal changes that occur, e.g., development of breasts and rounding of buttocks, are very disturbing to anorectics. There may be an unconscious fantasy of being masculine and having a penis.

\section{Developmental Issues}

As noted earlier, the symptoms of anorexia nervosa typically first manifest themselves during or soon after puberty. During adolescence earlier conflicts that have been unsuccessfully worked through may recur and become intensified as the adolescent again attempts to master her conflicts. Among the "goals" of adolescence, Kramer describes "intrapsychic separation from primary love objects, attainment of heterosexual object choice, and ultimate culmination of a well-defined sense of identity" (12).

Most anorectic patients describe feeling as if they have no identity of their own. They see themselves as imperfect and ineffective. The attainment of a secure sense of self results from the successful negotiation of the rapprochement subphase. Mahler has written extensively on the early interactions of mother and child, stressing the importance of the rapprochement subphase of separation-individuation (13). During rapprochement (from approximately age fifteen to twenty-two months), the child becomes increasingly aware of his physical separateness from his mother (or primary love object) and simultaneously desirous of her mother's attention and praise. The mother's libidinal availability during this period is of importance in the child's development of autonomy and trust. Mahler describes how the mother's inability to tolerate the inevitable frustrations and unpredictability of this phase may set up a neurotic fixation at this level, interfering with later oedipal development (13).

Sperling has observed the development of eating disorders in infants. She has found in analysis with the mothers that the mother often has highly ambivalent feelings toward the anorectic child (10). In the many case vignettes of anorectics that I have reviewed, as well as in my own experience, I have been struck by the apparent lack of empathy between mother and daughter. It seems to me that a similar emotional distance is likely to have existed between the mother and child during the early years of the child's life, leading to the anorectic's inner sense of discontent and insecurity.

Subsequently, the anorectic child's experience of the oedipal phase may be altered. Hogan reports an intense oedipal attachment to the father in these patients (14). This attachment becomes particularly threatening during the time of puberty. The regressive maneuvers characteristic of anorexia may be seen as an attempt to repress these conflicts.

\section{Case Report}

The patient was a twenty-one year old Caucasian female who was admitted to a general medical floor of a hospital having an initial weight of 82 pounds. Physical examination revealed bilateral pedal edea, dyspnea on exertion, amenorrhea, brady- 
cardia, and lanugo. Early in the course of her hospitalization organic causes were ruled out as etiologies for her weight loss, and she was diagnosed as having anorexia nervosa.

The patient admitted to a history of gradual weight loss over the last year that had become precipitously worse during the last few months preceding hospitalization. She stated it began as a diet because she was tired of being obese (reporting that she once weighed in excess of two hundred pounds). She did not feel that she looked too thin at 82 pounds; instead she was obsessed with not getting too fat. She denied that there was anything wrong with her eating habits; prior to hospitalization she ate only lettuce, raw vegetables, fruit, and clear broths. The only reason that she had consented to hospitalization was that her shortness of breath was interfering with her usual level of activity.

During initial sessions the patient was pleasant and very cooperative in trying to answer my questions. Of note was an almost total denial of any conflicts with her parents or sibling rivalry. She agreed verbally to the diet recommended for weight gain, but invariably found reasons to avoid eating food brought to her. When confronted about this, she responded that she was afraid that if she ever started eating "regular food" again that she would be unable to control her eating at all and become fat.

The social and developmental history of this patient is as follows. She is the second oldest of three children in an intact family. Her sister is two and one-half years older than she is, while her brother is one and one-half years younger. Her older sister is married and lives away from the home. Her younger brother became engaged to be married three months prior to the patient's hospitalization. The patient herself does not date. She lives at home and works part-time in the family business. She reasoned that she did not date in high school because "I was too fat," but even following her weight loss she still did not date, feeling too anxious with and angry at men. She said she felt that men were being "deceitful" by finding her attractive only when she was thin. At the same time, as she became more attractive to men, she became obsessed with the fear of becoming fat again.

Information about the patient's early years were pieced together from history given by both the patient and her mother. When she was eighteen months old, her brother was born with a congenital renal anomaly that required immediate surgery. $\mathrm{He}$ was seriously ill during the first few years of his life. During this time the patient's mother reports devoting most of her attention to the patient's brother. Concomitantly the patient was cared for by her paternal grandmother, with whom she developed a special relationship. The patient's mother became increasingly jealous of this relationship, feeling that her mother-in-law was "turning (the patient) against her." During her adolescence the patient's mother discouraged her from visiting this grandmother.

The patient reported that she never felt very close to her mother. She was, she said, closer to her father. Indeed, she described her senior year in high school as "the happiest in my life." During this year she lived together with her father and brother, while her mother moved to another state to start a new business. The patient had been president of her class in high school and was reluctant to move with her mother. 
During family interviews the patient's mother was the "spokesperson" for the family. She studiously denied any problems within the family, except for the patient's weight loss. She stated that she never interfered with her children's lives, adding that she "lets the children do whatever they want" (the "children" being twenty and twenty-one years old). When any mention was made of the jealousy between the patient's mother and the aforementioned grandmother, the patient became very upset, asking that "they not talk about it with Daddy here." Of note during these family sessions was the almost complete lack of interacton between the patient's mother and her father, the passivity of her father, and the presence of maternal grandparents who spoke no English.

Although the family expressed great concern over the patient's weight loss, as soon as she began to gain weight during her hospitalization they again denied that there was any serious problem within the family. The patient refused to consider subsequent short term psychiatric hospitalization after her medical condition stabilized. Her family supported this decision. She was discharged to outpatient psychiatric follow-up.

In reviewing this case, the patient met the criteria for the diagnosis of anorexia nervosa. She was obsessed with the pursuit of thinness. She was convinced that her body was larger than it actually was. During the months prior to hospitalization her weight had dropped steadily because of her refusal to eat.

Because of the brief duration of this patient's hospitalization (two weeks), it was not possible to uncover the specific unconscious fantasies that motivated her anorectic behavior. However, it was evident that she had severe conflicts around achieving heterosexual relationships. While she did not identify with her mother, the patient did develop an intense attachment to her father. Her anorectic symptoms may be seen as a defense against anxiety-producing oedipal conflicts that emerged during her early weight loss.

The family dynamics also reflect patterns described in the literature. The conflict-avoidance pattern was used by the patient's family. The mother was intrusive, but not empathetic with the patient, who often functioned as a go-between for her parents. The patient's family was enmeshed; they discouraged her from doing anything independent, such as going away to college. At least superficially, the patient was always concerned with pleasing her parents, grandparents, and brother.

\section{Countertransference Dilemmas}

In treating this patient I became aware of my own reactions to her therapy. After each session I became ravenously hungry, unable to think of anything else but food (until I ate something). I noticed that I never ate anything prior to the sessions and did not feel hungry during the sessions themselves, only afterwards. I realized that I was having mini-anorectic episodes.

In trying to understand my reaction, I began to see the ways in which I identified with this patient. She looked forward to our daily sessions, developing a relatively 
trusting alliance with me. In looking more closely at my reaction, I also realized that I had the wish to stop the patient's destructiveness by eating for her. But just as she denied any "negative" feelings towards her family, I became aware that I was denying any anger towards her. This is not to imply that my wish to help was simply reaction-formation. In a discussion of ethical dilemmas in treating suicidal patients, Ornstein and Kay state that the wish to help is not strictly counter-transferential. In part it results from "feelings common to all appropriately socialized human beings ... empathetic caring for the other, the basis of all ethics" (15).

A similar denial of countertransference hatred, along with a concomitant wish to save or help her, seemed to motivate many of the other hospital staff who participated in her care. One staff member in particular became quite anxious that the patient would begin acting out her need to control her oral intake, and recommended that the patient's bathroom door be locked so she could not dispose of unwanted food on the sly. The patient herself had given no indication that she was likely to do so. Another staff member decided unilaterally that the weight gain we had recommended for the patient (one-half pound per day) was "too much" for the patient and told her so. Of course the patient concurred with this staff person that the weight gain we had recommended was indeed excessive. In this manner divisiveness was created among the treating staff that in some ways replicated the patient's familial patterns.

Busie and Maltsberger comment on the deleterious effect of countertransference: "It may generate well rationalized but destructive acting out by the therapist" (16). They explain the defensive mechanism of reaction-formation against countertransference hatred by which negative feelings for the patient are defended against by an anxious concern for their welfare.

Bruch also warns against the possible deleterious effects of hospitalizing an anorectic patient on a medical service. Because the personnel are not trained to recognize many of the phenomena described above, they are apt to become anxious, frustrated, and angrily coercive with the patient. "Thus, a hospital stay may be characterized by the same type of frantic emergency situations that led to hospitalization in the first place" (1).

\section{Conclusion}

Anorexia nervosa appears to be rising in incidence among adolescent females. In this paper I have reviewed some of the family systems and intrapsychic conflicts that may be involved in the development of this syndrome. It is my belief that an understanding and acceptance of the importance of both approaches is essential to the successful treatment of the anorectic. I disagree with the claim of many psychoanalysts that hospitalization or external alteration of the anorectic's abnormal eating behavior is contraindicated (17). Because the mortality associated with anorexia is so high, I feel that the therapist must establish clear limits with the patient regarding what is a medically safe weight. Unlike other neurotic symptoms, self starvation is a potentially life threatening behavior that must be dealt with early in therapy. It is evident to me 
that long term intensive therapy is necessary in order to achieve a lasting change in the anorectic patient. Whether or not this is best accomplished through psychoanalysis or psychoanalytic psychotherapy is an important question that requires further study.

\section{REFERENCES}

1. Bruch H: Eating Disorders: Obesity, Anorexia Nervosa, and the Person Within. New York, Basic Books, 1973

2. Diagnostic and Statistical Manual of Mental Disorders, 3rd edition. Washington, American Psychiatric Association Press, 1980

3. Maloney M, Klykylo W: An overview of anorexia nervosa, bulimia, and obesity in children and adolescents. J Am Ac Ch Psych 22: 99-107, 1983

4. Newsweek, On Campus Edition, April 1984.

5. Bruch H: Eating Disorders: Obesity, Anorexia Nervosa, and the Person Within. New York, Basic Books, 1973

6. Halmi K: Anorexia nervosa and bulimia. Psychosom 24: 111-129, 1983

7. Bruch H: The Golden Cage. New York, Vintage Books, 1978

8. Brotman A, Stern T: Case report of cardiovascular abnormalities in anorexia nervosa. Am J Psych 140: 1225-1227, 1983

9. Minuchin S, Rosman B, Baker L: Psychosomatic Families, Anorexia Nervosa in Context. Cambridge, Harvard University Press, 1978

10. Sperling M: A re-evaluation of classification, concepts, and treatment, in Fear of Being Fat. Edited by Wilson C. New York, Jason Aronson, 1983

11. Walder R: The principle of multiple function: observations on overdetermination. Psychoanaly Quar 5: 45-62, 1936

12. Kramer S: Residues of split-object and split-self dichotomies, in Rapprochement, the Critical Subphase of Separation-Individuation. Edited by Bach S, Burland JA, Lax R. New York, Jason Aronson, 1980

13. Mahler M: Rapprochement subphase of the separation individuation process, in Rapprochement, the Critical Subphase of Separation-Individuation. Edited by Bach S, Burland JA, Lax R. New York, Jason Aronson, 1980

14. Hogan C: Psychodynamics, in Fear of Being Fat. Edited by Wilson C. New York, Jason Aronson, 1983

15. Ornstein P, Kay J: Ethical problems in the psychotherapy of the suicidal patient. Psych Ann 13: $332-340,1983$

16. Maltsberger J, Buie D: Countertransference hate in the treatment of suicidal patients, unpublished

17. Mintz I: The clinical picture of anorexia nervosa and bulimia, in Fear of Being Fat. Edited by Wilson C. New York, Jason Aronson, 1983 